\title{
Primary and secondary school mental health teachers in professional identity of intervention programs
}

\author{
Hao Lei, Cheng Guo*, Yanling Liu* \\ Faculty of Psychology \& Center for Students’ Mental Health, Southwest University, Chongqing, China; \\ *Corresponding Authors: guochen@swu.edu.cn, ssq@swu.edu.cn
}

Received 15 August 2012; revised 10 October 2012; accepted 19 October 2012

\begin{abstract}
To explore the impact of teacher training on the professional identity of primary and secondary school mental health teachers, this study conducted a half-month professional development training program to 54 primary and secondary school mental health teachers, and performed measurement on the professional identity of the teachers in the experimental group and the control group with "Teachers' Professional Identity Questionnaire". The result shows that after the training there is a significant improvement in the professional identity of the teachers in the experimental group, and the teachers' scores on the four dimensions of profession identity: the sense of role, the professional behavioral tendency, the occupational values, and the sense of belonging, all increased significantly. This indicates that the curriculum intervention for the primary and secondary school mental health teachers could effectively improve the teachers' professional identity.
\end{abstract}

Keywords: Primary and Secondary School; Mental Health Teachers; Professional Identity; Curriculum Intervention

\section{INTRODUCTION}

Currently in academic world, there is not a common understanding of Teachers' professional identity. Kremer and Hofman consider that teachers' professional identity consists of mainly four components: centrality, value, uniting, and self-expression [1]. Brickson thinks that teachers' professional identify is a three-factor model formed by personal factors, collective factors, and interactive factors [2]. Yu, H.H. suggests that teachers' professional identity involves teachers' professional ability, occupational sense, understanding of occupational char- acteristics, recognition of leadership, recognition of colleagues, recognition of students, recognition of work report, recognition of work background, sense of belonging to the school, judgment of the group sense, etc. [3]. Summarizing the existing studies comprehensively, Wei, S.H. defines teachers' professional identity as a synthesis of teachers' positive perception, experience, and behavioral tendency in their professional and internalized occupational role, mainly including the occupational values, the sense of role, the sense of belonging, and the professional behavioral tendency [4].

Professional identity is closely related to individual's career decisions, career exploration and career success; it influences the adaptability of a person in the complex occupational environment nowadays [5]. Some studies found a negative correlation between teachers' professional identity and their working pressure and turnover intention, which means the higher a teacher's professional identity is, the lower his/her working pressure and intention of leaving the workplace or job are [6]; similarly, the lower a teacher's professional identity is, the higher the level of his/her burnout is [7]. High professional identity could indirectly lead to better individual performance [8]. In an organization, increase employees' self-consciousness and professional identity would help to improve the organization's competitiveness in the market [9]; likewise, the improvement of teachers' professional identity could also raise the school's competetiveness effectively. Some Chinese researchers found that the teachers of special grade have significantly higher level of professional identity than ordinary teachers [10]. Thus, in-depth study of teachers' professional identity is important and valuable.

Mental health education, as a course, is gradually being carried out in primary and secondary schools; however the teachers of this course are still in the exploration phase of their occupation, with low level of professional identity in mental health education. For example, there were surveys show that primary and secondary school 
mental health teachers in China have fuzzy understanding of the objective and function of mental health education and unclear recognition of their job description, and are also lack of clear understanding of the role of mental health education [11]; some studies pointed out that currently job burnout are common in mental health teachers of primary and secondary schools, represented particularly by the decrease of the sense of individual accomplishment [12]. It is widely known that in primary and secondary schools, mental health teachers are the guides of students' mental healthiness; if these teachers have higher level of professional identity, they would more positively face and effectively solve the psychological problems of students; however if these teachers have lower level of professional identity, they are more likely to negatively respond to students' psychological problems, and solve students' psychological problems ineffectively. Therefore, it is necessary to take effective measures to improve the professional identify of the primary and secondary school mental health teachers, in order to improve the efficiency of mental health education and the healthy growth of students.

However, the current studies on the professional identity of Chinese teachers mainly focus on theoretical discussion and analysis of the present situation, intervention study on teachers' professional identify is rarely found, not mention intervention study that aimed at the professional identify of primary and secondary school mental health teachers. Therefore, to further expand the studies on professional identity especially the nurturing studies on the professional identity of primary and secondary school mental health teachers, this study intend to examine the impact of occupational training courses on these teachers' occupational values, sense of role, sense of belonging, and professional behavioral tendency, and then explore the intervention effect of the courses on the teachers' professional identity.

\footnotetext{
1“National Training Program" is short for the "National Training Program for Primary and Secondary School Teachers". This program was proposed on 2009, since then large number of special funds were invested by the government to ensure the smooth implementation of this program ("National Training Program is the first major program to be carried out for the implementation of the national education plan" $[13,14])$; currently the program is basically carried out based on the unit of provinces (or municipalities and autonomous regions). The themes of the program varies according to different types of disciplines while the purpose of all the themes is to improve the teaching skills of primary and secondary school teachers; the participants of the program are primary and secondary school teachers teaching different courses; training approach of the program is mainly to hire the teachers of colleges and universities to conduct trainings on professional knowledge and skills to the participants. The implementation of the "National Training Plan", on the one hand is to improve the teachers' professional skills, educational and researching attainment and other education skills, and on the other hand is to improve the teachers' occupational psychology in order to enhance their identity in education, ease their feeling of job burnout, reduce their turnover intention, and improve their enthusiasm in education.
}

\section{RESEARCH APPROACH}

\subsection{Subjects}

The subjects in the experimental group are 54 mental health teachers from the primary and secondary schools in Chongqing, and they all participated in the "National Training Program"1 of Chongqing; there are 26 primary school teachers and 28 secondary school teachers, where 16 of them are male teachers and 38 are female. The subjects in the control group are another 54 mental health teachers from the primary and secondary schools in Chongqing; 28 of them are primary school teachers and 26 are secondary school teachers, while 20 are male and 34 are female. The difference between the experimental group and the control group is that the subjects in the experimental group joined the training program for primary and secondary school mental health teachers while the subjects in the control group did not.

\subsection{Experiment Design}

Experiment is designed to use equivalent-group method, where the experimental and control groups are measured before and after the training program. The independent variable is the National Training Program for the mental health teachers of Chongqing, and the dependent variable is the professional identity of the teachers. The experiment lasted for two weeks.

\subsection{Study Tools}

The professional identity questionnaire designed by Wei, S.H. ("Teachers' Professional Identity Questionnaire”) [4] is used in this study; this scale contains 18 items in four dimension: the sense of the role (6 items), the professional behavioral tendency (5 items), occupational values (4 items), and the sense of belonging (3 items). The " $a$ " coefficient between the dimensions of this scale is in the range of $0.720-0.864$, and the "a" coefficient of the full scale is 0.893 ; the split-half reliability coefficient between the dimensions is between 0.744 and 0.862 , and the coefficient for the full scale is 0.834 . The factors of the scale show apparent correlation, the correlation coefficient is between 0.384 and 0.598 , which is a moderate association; and the factors also show significant correlation with the total score (0.709 0.842). Also, confirmatory factor analysis shows that, for each of the fit exponents, the value of $\mathrm{X}^{2} / \mathrm{df}$ is 4.531 , and the values of other exponents like GFI, AGFI, IFI, NFI, NNFI, and CFI are all above 0.90, the RMR is below 0.05 , and RMSEA is below 0.08, which all fulfill the requirement of an optimal fit model. Obviously, this questionnaire has good reliability and validity. In this study, the "a" coefficient between the dimensions of the scale is in the range of $0.758-0.878$, and the "a" 
coefficient of the full scale is 0.903; the split-half reliability coefficient between the dimensions is in the range of $0.735-0.889$, and for the full scale, it is 0.856 . The factors show significant correlation, with the correlation coefficient between 0.402 and 0.532 , which is a moderate association; and the factors of the scale also show significant correlation with the total score (0.732 0.869).

\subsection{Training Course Design of the Mental Health National Training Plan}

With the purpose of improve the professionalism and professional identity of the mental health teachers of primary and secondary schools in Chongqing, this training course is co-designed by a number of experts and excellent primary and secondary school teachers together. Courses in three themes are involved:

1) General education courses. General education courses mainly involve two section, "Psychological development and the basic principles of education, psychological diathesis, and mental health education” and "Principles and operations of psychological diathesis training and mental health education”. The former mainly includes the basic theories of developmental and educational psychology, and the basic principles of mental health education and psychological counseling; while the latter mainly involves the basic principles and skills of mental health education, the basic skills of psychological counseling, the design and implementation of mental health education courses, the theories and operational skills of group counseling, and the operational skills of individual psychological counseling, etc.

2) Investigation course. Investigations course is mainly for the methods and skills of promoting mental health education study in school. This course mainly includes the analysis of the research topics of mental health issues of the primary and secondary school students, and the researchers' role of the mental health teachers.

3) Effect assessment course. Effect assessment course mainly include the mental health assessment system for primary and secondary school students and the analysis of the system, as well as the operating skills of psychological assessment, the creation of students' psychological files, and the analysis of the school management system for the mental health education of students.

Finally, to combine theories with practice, this training program also involves field observation classes; and after each theory class, the trainees share and communicate with each other in order to better share and exchange their feelings and gains from the study.

\subsection{Steps and Methods of the Training}

Step 1: Identification and discrimination. Through self-tests, cognition change method, discussion, case analysis and other ways, let the subjects understand the situation of their professional identity in order to evoke their sense of identity in the course, as well as their emotional resonance and shock, so that they realize the function of professional identity, and form correct concepts of mental health education.

Step 2: Training strategy. By designing related activities, use model education, role play, debate, and sentiment to further inspire and educate the subjects, in order to stimulate their inner desire for mental health education, and guide them to think about and experience the skills of dealing with unhealthy occupational psychologies. Through group counseling, classroom lectures, practical operation and other means, support, encouragement and guidance are given to the teachers of primary and secondary schools for their occupational development, so that they could have the confidence to gradually overcome their own professional identity problem, and increase the level of their recognition to the mental health education career.

Step 3: Introspective experience. By problem presenting, extended practice, case summaries, self-reflection method, and before-and-after training comparison, the subjects could shift what they learned to similar contexts, and integrate the learned knowledge and skills.

\subsection{Experiment Process and Data Handling}

During October 25, 2011 to November 24, 2011, mental health teachers in the experimental group received a 15-day mental health teacher training. Respectively before the training and after the last training, pre-andpost training tests of professional identity are conducted to both the experimental group and the control group; the experimenter used unified instruction and questionnaire for the tests; the tests have no time limit. The data are analyzed with SPSS13.0 software on computer.

\section{RESULTS}

\subsection{Transverse Comparison of the Professional Identity of the Mental Health Teachers in the Experimental and Control Group}

Transverse comparison of the pre-and-post intervention test scores of the mental health teachers in both the experimental group and the control group on the professional identity full scale and each dimension are as shown in Table 1.

As shown in Table 1, before the intervention, the test scores of the teachers in the experimental and control group show no significant differences on the full scale as well as each dimension $(\mathrm{P}>0.05)$. In the post-intervention test, the teachers in the experimental group obtained 
Table 1. Transverse comparison of the professional identity of the primary and secondary school mental health teachers in the experimental and control group.

\begin{tabular}{ccccccc}
\hline & Variable & $\begin{array}{c}\text { Sense of Role } \\
(\mathrm{M} \pm \mathrm{SD})\end{array}$ & $\begin{array}{c}\text { Professional Behavioral } \\
\text { Tendency }(\mathrm{M} \pm \mathrm{SD})\end{array}$ & $\begin{array}{c}\text { Occupational } \\
\text { Values (M } \pm \text { SD) }\end{array}$ & $\begin{array}{c}\text { Sense of Belonging } \\
(\mathrm{M} \pm \mathrm{SD})\end{array}$ & $\begin{array}{c}\text { Overall Professional } \\
\text { Identity (M } \pm \text { SD) }\end{array}$ \\
\hline \multirow{3}{*}{ Pre test } & Experimental Group & $3.63 \pm 0.59$ & $4.30 \pm 0.43$ & $4.33 \pm 0.55$ & $3.60 \pm 0.94$ & $3.94 \pm 0.45$ \\
& Control Group & $3.77 \pm 0.55$ & $4.34 \pm 0.27$ & $4.45 \pm 0.43$ & $3.67 \pm 0.58$ & $4.08 \pm 0.30$ \\
& $\mathrm{~T}$ & -1.230 & -0.561 & -1.056 & -0.483 & -0.568 \\
\multirow{2}{*}{ Post test } & Experimental Group & $3.90 \pm 0.67$ & $4.58 \pm 0.48$ & $4.86 \pm 0.46$ & $4.59 \pm 0.56$ & $4.41 \pm 0.78$ \\
& Control Group & $3.72 \pm 0.64$ & $4.32 \pm 0.35$ & $4.43 \pm 0.39$ & $3.71 \pm 0.65$ & $4.04 \pm 0.30$ \\
& $\mathrm{~T}$ & 1.031 & $2.362^{* *}$ & $2.633^{* *}$ & $3.689^{* * *}$ & $2.382^{* *}$
\end{tabular}

Note: ${ }^{*} \mathrm{P}<0.05 ;{ }^{* *} \mathrm{P}<0.01 ;{ }^{* * *} \mathrm{P}<0.001$.

significantly higher scores on the full scale than the teachers in the control group $(\mathrm{P}<0.01)$; for the dimensions of "professional behavioral tendency", "occupational values", and "sense of belonging", the teachers in the experimental group also got much higher scores than the teachers in the control group ( $\mathrm{P}<0.01$ or $\mathrm{P}<0.001$ ); on the dimension of "sense of role" the scores of the teachers in both groups have no obvious difference $(\mathrm{P}>$ $0.05)$.

\subsection{Longitudinal Comparison of the Professional Identity of the Primary and Secondary School Mental Health Teachers}

Longitudinal comparison of the pre-and-post intervention scores of the mental health teachers in both the experimental group and the control group on the professional identity full scale and each dimension are as shown in Table 2.

As shown in Table 2, overall, the post-intervention test scores of the experimental group teachers on the professional identity scale is significantly higher than their pre-intervention test scores $(\mathrm{P}<0.001)$, which means after the intervention, the professional identity of the teachers in the experimental group is obviously improved. For the dimensions, the post-scores on "the sense of role" and "the occupational values" are extraordinarily higher than pre test scores $(\mathrm{P}<0.001)$, the post intervention test scores on "professional behavioral tendency" are also significantly increased $(\mathrm{P}<0.01)$, and the post-intervention test scores on "the sense of belonging" are less but also significantly higher than the pre-intervention test scores $(\mathrm{P}<0.05)$. Meanwhile, for the teachers in the control group, there is no significant difference between their pre-and-post intervention test scores on the teachers' professional identity full scale and each dimension.

\section{DISCUSSIONS}

\subsection{Feasibility of Psychological Curriculum Intervention to the Professional Identity of Primary and Secondary School Mental Health Teachers}

Teachers' professional identity is a complex system composed by multiple elements; it is not easy to perform educational intervention on it in limited period of time. This study shows that with the National Education Program as the ground, integrating the excellent mental health education resources of colleges and universities as well as primary and secondary schools, after scientific and rational curriculum intervention, the professional identity of the teachers in the experimental group is significantly improved, indicating that the professional identity of primary and secondary school mental health teachers can be improved through the enhancement of their professional standards. This study provides a reference for the future occupational psychology intervention for mental health teachers.

\subsection{Analysis of the Effect of Mental Health Curriculum Intervention Experiment}

The overall effect of the mental health curriculum intervention experiment is mainly reflected in the following: 1) the overall situation of the professional identity of the mental health teachers in the experimental group which was given mental health training is improved. Before the experiment, there is no significant difference between the professional identity of the mental health teachers in the experimental group and the control group; while after the intervention of a one-month training on mental health, either transversely or longitudinally, the professional identity of the teachers in the experimental group is significantly improved (as illustrated in Tables 1 and 2). 2) The curriculum intervention experiment had 
Table 2. Longitudinal comparison of the professional identity of the primary and secondary school mental health teachers in the experimental and control group.

\begin{tabular}{ccccccc}
\hline & Variable & $\begin{array}{c}\text { Sense of Role } \\
(\mathrm{M} \pm \mathrm{SD})\end{array}$ & $\begin{array}{c}\text { Professional Behavioral } \\
\text { Tendency }(\mathrm{M} \pm \mathrm{SD})\end{array}$ & $\begin{array}{c}\text { Occupational Values } \\
(\mathrm{M} \pm \mathrm{SD})\end{array}$ & $\begin{array}{c}\text { Sense of Belonging } \\
(\mathrm{M} \pm \mathrm{SD})\end{array}$ & $\begin{array}{c}\text { Overall Professional } \\
\text { Identity (M } \pm \text { SD) }\end{array}$ \\
\hline \multirow{2}{*}{ Experimental Group } & Pre Test & $3.63 \pm 0.59$ & $4.30 \pm 0.43$ & $4.33 \pm 0.55$ & $3.60 \pm 0.94$ & $3.94 \pm 0.45$ \\
& Post Test & $3.90 \pm 0.67$ & $4.58 \pm 0.48$ & $4.66 \pm 0.46$ & $4.59 \pm 0.56$ & $4.41 \pm 0.78$ \\
& $\mathrm{~T}$ & $-4.052^{* * *}$ & $-2.680^{* *}$ & $-4.927^{* * *}$ & $-2.139^{*}$ & $-4.095^{* * *}$ \\
& Pre Test & $3.77 \pm 0.55$ & $4.34 \pm 0.27$ & $4.45 \pm 0.43$ & $3.67 \pm 0.58$ & $4.08 \pm 0.30$ \\
& Post Test & $3.72 \pm 0.64$ & $4.32 \pm 0.35$ & $4.43 \pm 0.39$ & $3.71 \pm 0.65$ & $4.04 \pm 0.30$ \\
& $\mathrm{~T}$ & 0.717 & 0.863 & 0.632 & -0.646 & 0.465 \\
\hline
\end{tabular}

Note: ${ }^{*} \mathrm{P}<0.05 ;{ }^{* *} \mathrm{P}<0.01 ;{ }^{* * *} \mathrm{P}<0.001$.

significant influence on the improvement of the professional identity of the mental health teachers in all the four aspects of professional identity, which in detail is that the post-intervention test scores on "the sense of role" and "occupational values" are significantly higher than the pre-intervention test scores $(\mathrm{P}<0.001)$, the post-intervention test scores on the "professional behavioral tendency" are also significantly increased $(\mathrm{P}<0.01)$, and the post-intervention test scores on the "sense of belonging" are less but also significantly higher than the pre-intervention test scores $(\mathrm{P}<0.05)$ (as illustrated in Tables 1 and 2).

Why did these overall effects appear? The reasons are:

1) The mental health curriculum intervention strengthened the mental health teachers' understanding of mental health education, and raised the teachers' sense of role.

This study shows that curriculum intervention is conducive to the improvement of the mental health teachers' sense of role. For a long time, because of the influence of the examination-oriented education system, schools and teachers all consider that the teachers who teach the courses which present the students' academic level are more important, causing that mental health teachers are not given attention, as a result a negative sense of role formed in the mind of mental health teachers that they think their professional knowledge about mental health is useless in primary and secondary schools. In this curriculum intervention for mental health education, the instructors emphasized in different ways that mental health education helps teachers to understand the characteristics of the physical and mental developments of students and it would help teachers to educate the students according to the students' characteristics. This inspires the teachers' sense of professional accomplishment, which as a matter of fact is the pursuit of the primary and secondary school teachers [15]; when the teachers' sense of professional accomplishment is improved, they are more able to have positive understanding and assessment of their role. Therefore, the mental health curriculum intervention could enhance the mental health teachers' understanding of the importance of mental health education in primary and secondary schools, and improve the level of the teachers' sense of role.

2) The course strengthened the mental health teachers' experience of psychological counseling and mental health maintenance strategy, and then improved the their professional behavioral tendency.

This study shows that curriculum intervention could effectively improve the mental health teachers' professional behavioral tendency. There are mainly two reasons for such effect. First, due to the changes of the teachers' occupational values, changes occur to the professional behavioral tendency of the teachers. Because of the differences between disciplines, the mental health teachers of primary and secondary schools usually have lower status in school, which causes them a negative attitude in their mental health education for the students; however with the experts' persuasion and inspiration, these teachers' sense of value for the mental health education of primary and secondary school is corrected, while in general a person's sense of value would influence his/her behavioral tendency, thus the professional behavioral tendency of these teachers is improved. Second, the environment of the curriculum intervention changed the professional behavioral tendency of the mental health teachers. In this curriculum intervention, in addition of hiring of psychological counseling experts to analyze the problems exist in school counseling, some simulation scenes are also arranged, face-to-face communication between the experts and the trainees are also carried out, and all kinds of mental health education problems are discussed among the trainees; the nurturing of such harmonious environment and culture accords with a theory in evolutionary psychology that social environment and culture are the proximate causes for the change of psychological behaviors [16]. Therefore, the teachers' professional behavioral tendency was significantly improved.

3) The mental health curriculum intervention improved 
the mental health teachers' occupational values.

It is showed in this study that curriculum intervention could effectively improve the occupational values of the primary and secondary school mental health teachers. Occupational value is a cognitive and motivational mechanism which represents the teachers' conviction for their education career, and directly influences the teachers' objective setting, effort for achieve the goal, and persistence when facing difficulties [17]. With the training on the professional knowledge of the mental health teachers, the teachers understand their engaged primary and secondary school mental health education is gradually getting more attention and recognition, which enabled them to produce a positive vision in their future work, and furthermore, made them to maintain a positive attitude and optimistic enterprising spirit in their future work and build a long-term objective for their engagement in primary and secondary school mental health education.

4) The mental health curriculum intervention effectively improved the mental health teachers' sense of belonging.

It is also found in this study that curriculum intervention can effectively improve the primary and secondary school mental health teachers' sense of belonging. There are mainly three reasons for this. First, this training is a curriculum intervention with many mental health teachers as object, thus a platform is given to the teachers to communicate with each other about their worries and happiness in the mental health education in school so that their loneness that they are the only one or two in their schools engaged in mental health education could be broken, and meanwhile the curriculum intervention gives these primary and secondary mental health teachers a proper place to relief their bad emotions. Second, this curriculum intervention let the teachers realize that their fellow teachers also have occupational confusion in one way or another, so they realize the fact that occupational confusion is normal. Third, the instructors also ease the confusions the teachers have in mental health education, and guide them to feel the sense of belonging in mental health education career. Therefore, the mental health teachers' sense of belonging was improved effectively.

\section{ACKNOWLEDGEMENTS}

This study was supported by the fund of key construction disciplines of Project 211(NSKD11050), key construction disciplines of Project 211 (NSKD11059), and supported by "the Fundamental Research Funds for the Central Universities (SWU1209485)”.

\section{REFERENCES}

[1] Kremer, L. and Hofman, J.E. (1985) Teachers' profes- sional identity and burn-out. Research in Education, 34, 89-95.

[2] Brickson, S. (2000) The impact of identity orientation on individual and organizational outcomes in demographically diverse settings. Academy of Management Review, 25, 82-101.

[3] Yu, H.H. and Liu, Y.W. (2006) Study of present situation of middle school young teachers' professional identity. Hunan Normal University, Changsha.

[4] Wei, S.H. (2008) Study of teachers' professional identity. Doctoral Dissertations of Xinan University, Chongqing.

[5] Gao, Y., Qiao, Z.H. and Song, H.T. (2011) Present situation and future of professional identity study. Journal of Beijing Normal University (Social Sciences), 4, 47-53.

[6] Gaziel, H.H. (1995) Sabbatical leave, job burnout and turnover intentions among teachers. International Journal of Lifelong Education, 14, 331-338. doi:10.1080/0260137950140406

[7] Kremer-Hayon, L., Faraj, H. and Wubbels, T. (2002) Burn-out among Israeli Arab school principals as a function of professional identity and interpersonal relationships with teachers. International Journal of Leadership in Education, 5, 149-162. doi:10.1080/13603120110057091

[8] Hall, D.T. and Moss, J.E. (1998) The new protean career contract: Helping organizations and employees adapt. Organizational Dynamics, 26, 22-37. doi:10.1016/S0090-2616(98)90012-2

[9] Hall, D.T. and Chandler, D.E. (2005) Psychological success: When the career is a calling. Journal of Organizational Behavior, 26, 155-176. doi:10.1002/job.301

[10] Zhang, S.S. (2011) Comparative study of special grade teachers and ordinary teachers' professional identity. Theory and Practice of Education (Primary and Secondary School Education), 31, 34-36.

[11] Sun, X.Q., Yu, R. and Tian, H.Y. (2005) Analysis of present situation of mental health teachers in elementary education and study of countermeasure. Journal of Chaohu College, 7, 148-149.

[12] Zhou, Y. (2009) Present situation, cause, and countermeasure of primary and secondary school mental health teachers' burn-out. Education Exploration, 11, 86-87.

[13] Guan, P.J. (2010) Build high-quality professional teaching staff. Reform Trends of Elementary Education, 17, 2931.

[14] Zhu, X.D. (2010) Values of "national training program”. Teacher Education Research, 6, 8.

[15] Xiang, Z.Q., Liu, M. and He, B.F. (2010) Analysis of relationship between primary and secondary school teachers' occupational values and job burn-out. Educational Research and Experiment, 2, 42-45.

[16] Li, H.L. and Zhang, L. (2010) Impacts of courtship motive on male's risk behavior tendency. Acta Psychologica Sinica, 42, 618-624. doi:10.3724/SP.J.1041.2010.00618

[17] Kyriacou, C. (2001) Teacher stress: Directions for future research. Educational Review, 53, 34. 